\title{
Os caminhos das águas: As políticas públicas ambientais e criação dos Comitês de Bacias Hidrográficas
}

\author{
Vera Lúcia Freitas Marinho* \\ Edvaldo Cesar Moretti ${ }^{* *}$
}

\section{Resumo}

O artigo é um ensaio sobre as políticas públicas ambientais voltadas aos recursos hídricos contextualizados nos caminhos da criação dos comitês de bacia hidrográfica. Tais questões, cada vez mais, encontram-se presentes nos fóruns internacionais, nacionais e regionais. A metodologia fundamenta-se nas abordagens $\mathrm{e}$ enfoques de referenciais que tenham novas ou outras formas de conceber a racionalidade e objetividade científica. Nesta discussão, não se pode ocultar que na essência da abordagem técnicocientífica há um conteúdo político e filosófico. Nesse sentido, tal artigo contribui no exercício de ampliar o olhar sobre a discussão da produção e apropriação da natureza, tratando das políticas públicas orientadas aos recursos hídricos.

Palavras-chave: Políticas públicas de recursos hídricos; Comitês de bacias hidrográficas; Usos das águas; Produção da natureza.

* Docente/Universidade Estadual de Mato Grosso do Sul/UEMS. Doutoranda/Programa de Pós-Graduação em Geografia/Unicamp/ IGCE (marinho_vera@yahoo.com.br).

** Docente/Universidade Federal da Grande Dourados/ UFGD. Professor do Programa de Pós-Graduação em Geografia/Unicamp/IGCE (ecmoretti@hotmail.com).

Geosul, Florianópolis, v. 28, n. 55, p 123-142, jan./jun. 2013 
MARINHO, V.L.F. \& MORETTI, E.C. Os caminhos das águas: As políticas...

The ways of water: The environmental public policies and creation of River Basin Committees

\section{Abstract}

The article is an essay on the environmental public policies geared to water resources contextualized in the ways of creation of river basin committees. Such issues, increasingly, are present in international, national and regional forums. The methodology is based on the approaches and benchmarks that have new or different ways of conceiving the rationality and scientific objectivity. In this discussion, we can not hide the fact that the essence of the scientific-technical is a political and philosophical approach. In this sense, this paper contributes to broaden perspectives on the discussion of production and appropriation of nature, dealing with public policies on water resources.

Key words: Public policies water resources; River basin committees; Uses of water; Production of nature.

\section{Introdução}

A partir de pesquisas, da participação em processos de constituição de comitês de bacias hidrográficas e de diálogos com sujeitos que vivenciam as práticas da gestão de recursos hídricos, algumas inquietações teórico-conceituais surgiram sobre a unidade analítica da bacia hidrográfica utilizada no âmbito das políticas públicas ambientais como unidade de análise físico-territorial, e adotada em pesquisas acadêmicas como base territorial ao planejamento e modelos de gestão de recursos hídricos, tanto na esfera pública, quanto na privada.

O entendimento sobre políticas públicas passa pelas dimensões de suas origens, seja social ou político-institucional. Nesse sentido, destaca Boneti (1997), as políticas públicas podem ser compreendidas como 
MARINHO, V.L.F. \& MORETTI, E.C. Os caminhos das águas: As políticas...

[...] a ação que nasce do contexto social, mas que passa pela esfera estatal como uma decisão de intervenção pública numa realidade social determinada, quer seja ela econômica ou social; e/ou [...] um conjunto de ações atribuídas à instituição estatal, que provoca o direcionamento (e/ou o redirecionamento) dos rumos dos investimentos na escala social e produtiva da sociedade (BONETI, 1997. p.19-20 grifo nosso).

As políticas públicas são estabelecidas no âmbito das relações de poder, tanto por grupos econômicos e políticos quanto por classes sociais ou demais organizações da sociedade civil. Neste caso, o Estado pode assumir o papel de agente repassador à sociedade civil das decisões saídas dos instrumentos políticoinstitucionais adotados como política pública de âmbito estadual e nacional, como nos modelos de gestão dos recursos hídricos.

Notadamente, durante o final do século XX, motivadas principalmente pela preocupação com o desequilíbrio entre o ritmo da produção de mercadorias e a capacidade de reprodução da natureza, as políticas públicas foram orientadas a absorver ações e práticas que considerassem as chamadas questões ambientais, tornando-se cada vez mais presentes os diálogos sobre ambiente, conservação e desenvolvimento nos fóruns internacionais, nacionais e locais.

Neste contexto de debate e na busca de soluções, principalmente voltadas para o interior do capital, "os problemas ambientais deixaram de ser considerados como locais e passaram para a órbita do mundial" (RODRIGUES, 2001. p.7). Especificamente sobre as águas, a Organização das Nações Unidas definiu o ano de 2013 como o Ano Internacional de Cooperação pela Água, indicando claramente o caráter mundial do debate sobre a escassez de água no planeta.

A fundamentação teórico-metodológica adotada para esta análise aborda enfoques que tenham novas ou outras formas de conceber a racionalidade e a objetividade científica. Sobre isso, Ferraz (2008) destaca que, 
MARINHO, V.L.F. \& MORETTI, E.C. Os caminhos das águas: As políticas...

[...] após a Teoria da Relatividade, do surgimento da Física Quântica, da Geometria Não-Euclidiana de Lobatchevski, da Álgebra de Boole, da nova Termodinâmica e do DNA, os tradicionais modelos rígidos e definidores de uma realidade objetiva e plenamente mensurável, sem improvisações ou fatores aleatórios, que as antigas ciências naturais defendiam, começaram a ser reavaliados (FERRAZ, 2008. p.37).

Conforme o autor (op. cit.) ao insistir na perspectiva de um racionalismo científico fechado e linear no qual não exista contradição, corremos o risco de reforçarmos as produções reducionistas e/ou simplistas da lógica do discurso final pronto e acabado. E conceber a ideia absoluta e unitária de produzir conhecimento científico pode levar a padronizar a diversidade do real. Isso implica que um método não pode mais ser tomado como único e absoluto em si.

Para Boaventura de Souza Santos (1995) o paradigma emergente do conhecimento tende a ser um conhecimento não dualista e deve visar superações das distinções tão familiares e óbvias que até há pouco tempo considerávamos insubstituíveis, tais como: "natureza/cultura, natureza/artificial, vivo/inanimado, mente/matéria, observador/observado, subjetivo/objetivo, coletivo/individual, animal/pessoa" (DE SOUSA SANTOS, 1995. p.39-40).

Nesse sentido, Leff (2001) afirma que o caminho da produção de conhecimentos deve ser a partir do diálogo com novos e outros saberes, gerando assim formas híbridas e integradas do conhecimento. Sobre a temática ambiental é ressaltada a necessidade de um olhar diferenciado voltado ao reconhecimento da construção do conhecimento, não por via única, mas por integração da prática entre os diversos saberes. Portanto, o conhecimento não pode se dar como acabado, mas em processo de construção; não neutro, mas estratégico, atravessado por relações de poder, seja no âmbito social, ambiental, econômico e/ou político. 
MARINHO, V.L.F. \& MORETTI, E.C. Os caminhos das águas: As políticas...

Por isso que no debate atual, cada vez mais, admitem-se temáticas não exclusivas e estanques ao domínio de campos de conhecimento ou linha da ciência. Nesse viés, Gonçalves (2002), exemplificando os estudos de mudanças climáticas, afirma:

[...] a mudança climática deixa de ser um tema exclusivo de geógrafos, físicos e meteorologistas e ser torna objeto de debate político [...] Acrescenta-se, ainda, o enorme interesse que instituições de pesquisa de ponta, como a NASA, vem manifestando pelo elevadíssimo índice de acerto de previsões do tempo meteorológico que fazem peritos das populações tradicionais do sertão semiárido do nordeste brasileiro, peritos esses nunca entraram numa escola formal (GONÇALVES, 2002. p. 221- grifo nosso).

Ao admitir, na construção do conhecimento, a necessidade da revalorização de saberes que, muitas vezes, não representam ou se qualificam com pretensões de cientificidades, Boneti (1997) questiona: para ser científico e racional é necessário ignorar as experiências de vida da população e sua cultura? Trata-se uma linha tênue na qual "não se pode separar alguns elementos básicos que permeiam a relação homem natureza, como é caso da produção material, dos traços culturais do homem e do meio ambiente" (BONETI, 1997, p. 14).

No âmbito ambiental Gonçalves (2002) observa o estabelecimento de grande tensão entre os gestores territoriais nacionais, militantes e, sobretudo, entre os gestores que operam em escalas, do local ao global. Há uma tendência para a conformação de uma ordem global (imperial) com enorme legitimidade, talvez só comparável aos direitos humanos. E, aqui, não poderia ser maior o conjunto de contradições que faz emergir entre territorialidades distintas, pois

[...] o debate acerca da diversidade biológica tem, de um lado, todo o setor industrial ligado à biotecnologia e, por outro lado, proporciona a possibilidade de múltiplos povos 
MARINHO, V.L.F. \& MORETTI, E.C. Os caminhos das águas: As políticas...

e culturas se apresentarem à cena política (GONÇALVES, 2002, p. 241 - 242).

Nesse sentido, o tema da diversidade biológica transcende o acadêmico, torna-se de interesse dos grandes grupos empresariais como também daquelas populações que detém conhecimentos preciosos sobre espécies animais e vegetais e que hoje disputam os direitos de propriedade intelectual. Portanto, a temática ambiental expõe dimensões, como às apontadas por Gonçalves (2002) que

[...] ficam indefinidos não só os limites entre as ciências, mas, também, entre diferentes modos de conhecer, já não sendo possível traçar com tanta certeza o limite entre quem sabe e quem não sabe (GONÇALVES, 2002. p. 221).

Ao considerar a complexidade de tal temática, surgem intermediações entre as políticas públicas dos recursos hídricos e o domínio da natureza. Trata-se de determinar usos diferenciados dos recursos hídricos e, portanto, de apropriação e valoração dos elementos da natureza.

\section{As políticas públicas dos recursos hídricos e a criação dos comitês de bacias hidrográficas}

As primeiras iniciativas nacionais para a institucionalização de políticas públicas de gestão da água são da década de 1920. Com finalidades específicas à gestão de águas, o Código das Águas é apontado como o mais antigo texto sobre o tema. Instituído em 1934, o Código das Águas passou a ser um marco como o único instrumento legal abrangente e específico sobre os recursos hídricos no país, assim permanecendo até o final da década de 1990 (CARVALHO, 2009).

Conforme Magalhães Júnior (2007) o Código de Águas aborda questões atuais da gestão de recurso hídricos, entre as quais, destaca-se, no texto do Art. 36, a referência ao princípio de usuário-pagador como indicação para aplicação da cobrança pelo uso da água. E no Art. 43 refere-se à outorga, estabelecendo: 
MARINHO, V.L.F. \& MORETTI, E.C. Os caminhos das águas: As políticas...

[...] as águas públicas não podem ser derivadas para as aplicações da agricultura, da indústria e da higiene e a existência de concessão administrativa, no caso de utilidade pública, e, não se verificando esta, de autorização administrativa, que será dispensada, todavia, na hipótese de derivações insignificantes (MAGALHÃES JÚNIOR, 2007, p. 123).

No entanto, destaca o autor (op. cit.), o Código de Águas reunia um sistema de regras formais que, de forma progressiva, acarretou um controle dos recursos hídricos voltado aos interesses setoriais, como foi o caso da CVSF - Comissão do Vale do São Francisco, criada em 1948, priorizando a expansão da agricultura irrigada.

Na segunda metade do século XX, o Estado brasileiro sob a influência do modelo americano TVA - Tennessee Valley Authority, de 1933, adota, em âmbito nacional, iniciativas pautadas em ações desenvolvimentistas e, no caso específico dos recursos hídricos, pode ser destacado:

[...] a forte expansão da Eletrobrás a partir dos anos 60, em parte devido à construção da Hidroelétrica de Itaipu e à criação da Eletronorte (Centrais Elétrica do Norte do Brasil) em 1972, a qual abriu caminho a um contínuo processo de construção de diversas barragens, a maioria de grande porte, na região amazônica (MAGALHÃES JÚNIOR, 2007, p. 122).

Ao considerar os interesses de políticas de Estado da época, tais iniciativas, além de incipientes na prática, reafirmavam os interesses setoriais, gerando um monopólio de poder administrativo pelo setor elétrico, refletindo na desarticulação institucional e fragmentação de políticas públicas de recursos hídricos. Assim, por mais de duas décadas (1970 e 1980), os setores elétrico e de saneamento tornaram-se os dois pilares das políticas públicas federais de recursos hídricos nacionais.

As mudanças são apontadas a partir das últimas décadas do século XX, momento histórico de manifestações por parte de muitos setores da sociedade na busca de ampliar as discussões 
MARINHO, V.L.F. \& MORETTI, E.C. Os caminhos das águas: As políticas...

sobre os problemas ambientais e a gestão participativa dos recursos hídricos. Fato que "tornou-se iminente a reavaliação do quadro legal institucional federal, visando comportar um tratamento diferente às questões ambientais antes consideradas temas secundários nos programas de desenvolvimento do governo" (MAGALHÃES JÚNIOR, 2007, p. 128).

Dessa forma, o processo de discussões e tramitação legal iniciado na década de 1980 foi encaminhado oficialmente à Constituição Federal de $1988^{1}$. Tal momento caracteriza-se como um marco histórico, um divisor de águas, do ponto vista da construção político-institucional do sistema de gestão nacional de recursos hídricos. Entretanto, houve críticas à Constituição uma vez que esta se apresenta como "centralizadora, confusa e cheia de lacunas na temática dos recursos hídricos" (CBH-PCJ, 2000. apud. MAGALHÃES JÚNIOR, 2007, p.129).

Nacionalmente, a partir do ano 1997, com promulgação da Política Nacional dos Recursos Hídricos - Lei no . 9.433/97² - são normatizados os comitês de bacias hidrográficas (CBHs) como integrantes do Sistema Nacional de Gerenciamento de Recursos Hídricos. $\mathrm{O}$ ato formaliza, entre outras ações, a outorga ${ }^{3}$ dos direitos de uso dos recursos hídricos e a cobrança pelo uso das

${ }^{1}$ CONSTITUIÇÃO DA REPÚBLICA FEDERATIVA DO BRASIL DE 1988, Art. 21, inciso XIX.

2 Institui a Política Nacional de Recursos Hídricos, cria o Sistema Nacional de Gerenciamento de Recursos Hídricos, regulamenta o inciso XIX do art. 21 da Constituição Federal, e altera o art. $1^{\circ}$ da Lei ${ }^{\circ}$ 8.001, de 13 de março de 1990, que modificou a Lei $\mathrm{n}^{\circ} 7.990$, de 28 de dezembro de 1989 (Lei no 9.433 de 08 de janeiro 1997). Disponível em: <http://www.planalto.gov.br>. Acesso em: dezembro 2012.

3 Outorga: autorização, concessão permissão. É o ato administrativo mediante o qual o poder público outorgante (União, estado ou Distrito Federal) faculta ao outorgado (requerente) o direito de uso de recurso hídrico, por prazo determinado, nos termos e nas condições expressas no respectivo ato administrativo (ANA - Agência Nacional de Águas 2012. Disponível em: <www.ana.gov.br> Acesso em dezembro 2012). 
MARINHO, V.L.F. \& MORETTI, E.C. Os caminhos das águas: As políticas... águas, ambas previstas, desde 1934, pelo texto do Código de Águas (CASTRO, ALVARENGA, MAGALHÃES JÚNIOR, 2005).

Como resultado dessa política nacional, gradativamente esta se implantando os mecanismos de cobrança pelo uso de recursos hídricos. Conforme dados apresentados pela Agência Nacional das Águas (ANA, 2012. p.144) ao longo do ano de 2011, a cobrança pelo uso das águas em rios de domínio da União e dos estados resultou numa arrecadação total de $\mathrm{R} \$ 131$ milhões. Os recursos arrecadados pela cobrança do uso de recursos hídricos de domínio da União são integralmente repassados pela ANA para as entidades delegatórias de funções da agência de água da bacia em que os recursos foram gerados ${ }^{4}$.

Segundo a ANA (2012) os recursos devem ser aplicados em ações de planejamento e gestão da bacia hidrográfica, conforme orientações previamente aprovadas por seus respectivos comitês de bacia hidrográfica. Entre as ações previstas para aplicação dos recursos encontram-se os projetos de educação ambiental, mobilização, capacitação e campanhas de incentivo ao uso racional da água. Como exemplos de ações de planejamento são citados a elaboração de planos diretores municipais e de projetos de esgotamento sanitário. Com relação às ações estruturais são orientadas as construções de sistemas de tratamento de esgotos, a recuperação de mananciais e o controle de erosão.

Para atuar nesse sentido, articula-se nos comitês de bacias hidrográficas os mecanismos para tomada de decisões na destinação de aplicação de recursos públicos em ações de políticas públicas voltadas aos recursos hídricos. Contudo, deve ser ressaltado, os comitês de bacias hidrográficas (CBHs) encontramse em processo de consolidação enquanto instrumentos do Sistema Nacional de Gerenciamento de Recursos Hídricos e, até momento, há situações inquietantes, principalmente quanto à valoração dos

${ }^{4}$ Previsto por meio de contratos de gestão regulamentados pela Lei 10. $881 / 2004$. 
MARINHO, V.L.F. \& MORETTI, E.C. Os caminhos das águas: As políticas...

recursos hídricos, sobretudo nas regiões com problemas de escassez hídrica ou de qualidade de água, sinalizando disputas pelo controle político-institucional, bem como uma pressão sobre os órgãos fiscalizadores dos mecanismos de gestão dos recursos hídricos.

Esses embates são desafios que passam, necessariamente, pela reflexão sobre a política pública destinada aos recursos hídricos e o entendimento da valoração das águas e produção da natureza na sociedade contemporânea.

Nessa discussão, conforme proposto por Rodrigues (2001) entendemos que os conceitos de natureza são construções sociais e alteram-se no tempo e no espaço. Portanto,

[...] o que se chama natureza pode ter vários significados dependendo dos diferentes grupos sociais, mas sempre é um conceito abstrato. [...] uma das formas de minimizar a abstração é compreender que a natureza e seus elementos são territorializados (RODRIGUES, 2001, p.1-3).

Ao abordar sobre a produção da natureza surgem intermediações sobre as disputas e o controle da água nas escalas local, regional, nacional e global, envolvendo expressões de poder territorial, econômico, político, administrativo e institucional.

Associada aos preceitos de conservação ambiental a criação dos comitês de bacias hidrográficas pode apresentar-se como representações de instâncias de poder e, ao mesmo tempo, sob outras ou novas territorialidades delimitadas e cartografadas por leituras geográficas de bacias hidrográficas.

Por essa razão, ao adotar tal compreensão de território, assume-se que na criação dos comitês de bacias hidrográficas há um conjunto de informações locais, externamente definidas, vinculadas a um conteúdo técnico e político e que pode expressar nas delimitações cartográficas da bacia hidrográfica informações locais ou regionais vinculadas às políticas públicas e relações de controle e poder sobre os usos das águas. 
MARINHO, V.L.F. \& MORETTI, E.C. Os caminhos das águas: As políticas...

Ao analisar abrangência desses enfoques, apontamos a necessidade de discutir e ampliar as perspectivas de leituras e de olhares analíticos tendo em vista as possibilidades de contribuições e aprimoramento dos elementos teórico-conceituais, tanto no âmbito acadêmico quanto nos planos e ações de políticas públicas voltadas aos recursos hídricos.

\section{A bacia hidrográfica: unidade territorial nos fóruns de decisões}

O uso da unidade territorial da bacia hidrográfica segue uma tendência internacional bem difundida em diversos países, como França, Alemanha, Inglaterra e Estados Unidos ${ }^{5}$, passando a ser adotada como referência e modelo de orientação para outros países.

Conforme Carvalho (2009), o modelo de gestão de bacias na América Latina data do fim dos anos 40. No Brasil, a ideia é aplicada desde 1948 devido à Comissão do Vale do São Francisco (CVSF). Até a década de 1970, considerando o quadro de interesses políticos do Estado da época, de modo geral a bacia hidrográfica era adotada como recorte territorial em programas nacionais e regionais relacionados ao desenvolvimento de projetos de grandes obras hidráulicas, voltados ao aproveitamento do potencial de recurso hídricos, geração de energia elétrica, transporte fluvial, sistemas de irrigação e drenagem, abastecimento de água potável e saneamento.

Nas últimas décadas do século $\mathrm{XX}$, o uso da bacia hidrográfica como unidade territorial assume a perspectiva de gestão participativa nas políticas públicas de recursos hídricos, voltada, essencialmente, a um enfoque político-institucional e administrativo.

Nessa perspectiva, a partir da Constituição de 1988, são estabelecidos parâmetros legais de domínio público da água (águas federais e estaduais) e o uso da bacia hidrográfica como unidade territorial para implementar a Política Nacional Dos Recursos

${ }^{5}$ Desde 1933, com o projeto Tennesse Valley Authority (TVA). 
MARINHO, V.L.F. \& MORETTI, E.C. Os caminhos das águas: As políticas...

Hídricos e atuação do Sistema Nacional de Gerenciamento de Recursos Hídricos - SNGRH (Lei 9.433/97).

Por esse motivo, a bacia hidrográfica é adotada como unidade territorial de planos e políticas de exploração de usos múltiplos, como, por exemplo, a geração de energia hidroelétrica, controle de enchentes, a transposição e a irrigação. Para isto, são frequentes os investimentos, tanto do setor público quanto da iniciativa privada, em soluções tecnológicas que, em curto prazo, atenuam os problemas. Entretanto, em muitos casos, tal procedimento tem gerado alto custo econômico, social e ambiental (SHIVA, 2006).

Ao considerar tais questões, Caetano (2003) analisa a represa Billings ${ }^{6}$, localizada no município de Santo André (SP), construída entre 1927 e 1937, como resultado de uma audaciosa obra de engenharia de reversão de águas da bacia do rio Pinheiros, destinada à geração de energia elétrica para o polo industrial de Cubatão, localizado no litoral paulista.

De acordo com o autor (op. cit.), a partir de 1950, as águas da represa passaram a ter múltiplos usos, como geração de energia, lazer, turismo e abastecimento público de água potável ${ }^{7}$, passando a servir também, nos períodos das chuvas, como fonte de recarga de água para drenagem das bacias do Tietê e Pinheiros, com o objetivo de minimizar os problemas das enchentes na capital paulista. No entanto, nas décadas seguintes, com a crescente deterioração da qualidade das águas da represa, o sistema de

${ }^{6}$ Projetada pelo canadense Asa Kenney Billings, a represa é formada pelo represamento das águas das bacias dos rios: Grande, Pequeno, Capivari, Pedra Branca, Taquacetuba, Alvarenga, Bororé, Cocaia e outros contribuintes menores. Drena uma área de $560 \mathrm{~km}^{2}$, resultando em vazão total de $16,3 \mathrm{~m}^{3} / \mathrm{s}$, correspondendo uma área inundada de 172 $\mathrm{km}^{2}$ (CAETANO, 2003.p.261).

${ }^{7}$ A partir de 1958, a Billings passou a servir como fonte de abastecimento de água potável à população dos municípios de Santo André, São Bernardo do Campo, São Caetano e Diadema. 
MARINHO, V.L.F. \& MORETTI, E.C. Os caminhos das águas: As políticas... abastecimento público ficou comprometido. Nas últimas décadas, os problemas se agravaram, exigindo que intervenções fossem realizadas, como a ocorrida em 1992, quando,

[...] com base na nova Constituição paulista, foi suspenso o bombeamento do rio Pinheiros em direção à represa Billings, criando-se normas para o bombeamento de emergência, que só poderia ocorrer para evitar dano a pessoas e bens em decorrência de excesso ou falta de águas na bacia do Alto Tietê (CAETANO, 2003, p. 263).

No caso da Billings, ao considerar sua localização, a demanda por água potável aliada a escassez de fontes de abastecimento tornam-se estratégicas no abastecimento de água potável da capital paulista e de seu entorno. Contudo, as medidas técnicas de intervenções muitas vezes têm gerado limitações e não o seu melhor uso.

As soluções tecnológicas de controle sobre a exploração dos recursos hídricos em geral exigem investimentos de recursos públicos e estabelecimento de regras para os usos que, nem sempre, ocorrem de forma equitativa entre os usuários do setor público e privado. Por isso, durante as negociações há a necessidade estabelecer os limites, tanto do ponto vista social e ambiental quanto das intervenções pelo poder público e privado (PACGNOCCHESCHI, 2003).

Ao considerar o comitê de bacia hidrográfica como um espaço de decisão, intermediando conflitos em tempos distintos ou não, pode-se direcionar e organizar os diversos interesses envolvidos. Portanto, do ponto de vista da gestão, a base conceitual de bacia hidrográfica gera limitações, dificuldades e desafios.

Atualmente, um dos principais desafios para a operacionalização dos $\mathrm{CBHs}$ federais e justamente a compatibilização da gestão por bacias hidrográficas em um sistema federativo no qual os interesses estaduais não são sempre convergentes (MAGALHÃES JÚNIOR, 2007. p.129). 
MARINHO, V.L.F. \& MORETTI, E.C. Os caminhos das águas: As políticas...

Dessa forma, há o conflito a partir da definição e sobreposição das bacias hidrográficas formadas por rios de domínio estaduais e as formadas pelos rios de domínio federal. Outra questão são as especificidades das bacias hidrográficas brasileiras, como o que ocorre em localidades da região Nordeste, onde a rede hidrográfica possui muitos rios intermitentes, ou da região Norte, onde há rios em escala amazônica.

Conforme Pacgnoccheschi (2003), no Nordeste, a dependência de obras hídricas reforça o surgimento das associações de usuários que se reúnem de modo alternativo para uma gestão participativa e, especialmente para esses casos, os comitês ou as associações precisam de outra perspectiva conceitual de unidade territorial para a gestão dos recursos hídricos. No caso dos rios amazônicos, como organizar ou articular comitês em escala de bacias? Características como a densidade populacional e as distâncias continentais entre localidades na mesma bacia, bem como as realidades das populações residentes, levam a um universo de percepção, ou não, dos conflitos distintos e distantes.

Nessa perspectiva, ao analisar a multiplicidade da realidade brasileira, questões técnicas e práticas assumem relevância, como, por exemplo, a disponibilização de dados socioeconômicos, censitários e de infraestrutura que são coletados e apresentados por municípios e, nestes casos, não estão associados aos limites de bacias hidrográficas ${ }^{8}$. Portanto, considerado essa complexidade, na aplicação de métodos de sobreposição de dados às análises podem ficar fragilizadas.

Ao observar os exemplos em localidades onde há obras de engenharia como os açudes, cisternas e reservatórios para geração de energia elétrica e abastecimento público urbano, bem como as

${ }^{8}$ Segundo Santos (2004, apud Carvalho 2009), no Brasil, as bases de dados cartográficos são disponibilizadas em escalas de 1: 50.000 e 1: 100.000. Isso resulta num alto custo para trabalhar com imagens de alta resolução e, em termos, dificulta o detalhamento de dados para os estudos. 
MARINHO, V.L.F. \& MORETTI, E.C. Os caminhos das águas: As políticas... reversões e transposição de bacias, têm surgido formas de associações de usuários que, necessariamente, não se constituem sob a perspectiva de abordagem da unidade territorial da bacia hidrográfica. Nesse caso, como identificar todos os atores sociais diretamente interessados no uso e manejo das bacias ou ainda como promover o debate no processo de tomada de decisões? Conforme Magalhães Júnior (2009),

[...] os usuários da água são muito mais conectados, no sentido da percepção, ao seu espaço próximo, incluindo trechos de rios. Em geral, o cidadão não tem visão global da bacia onde vive. [...] a bacia hidrográfica não possui identidade sociológica, administrativa ou política, e não traz geralmente, como apregoado, a noção de espaço funcional de gerenciamento (MAGALHÃES JÚNIOR, 2009. p 140).

Portanto, considerando os modelos de gerenciamento dos recursos hídricos através das experiências dos comitês de bacia hidrográfica, tais iniciativas parecem enriquecer o processo participativo local, mas podem, por outro lado, dificultar o equacionamento de discussões em escalas maiores, como as requeridas por bacias hidrográficas.

Assim, o conceito integrador de bacia hidrográfica não é unânime. Na perspectiva da gestão, ele comporta obstáculos, limitações e fragilidades. Portanto, parece razoável considerar o desafio de que a unidade territorial da bacia hidrográfica pode não exercer a função integradora prevista, apontando na produção do conhecimento a necessidade de discutir a temática sob outras possibilidades de leitura e entendimento.

\section{Considerações Finais}

O artigo tratou da temática nos "caminhos das águas", indicando o caráter mundial do debate sobre conflitos no uso, apropriação e escassez de água no planeta. Tal discussão mantémse, desde o final do século XX, eminente nos fóruns internacionais, nacionais e regionais. Devido a este fato, a Organização das 
MARINHO, V.L.F. \& MORETTI, E.C. Os caminhos das águas: As políticas...

Nações Unidas definiu o ano de 2013 como o Ano Internacional de Cooperação pela Água.

Desse modo, as reflexões propostas argumentaram referenciais teórico-metodológicos destinados às pesquisas que refletem investigações realizadas sob o olhar da geografia das águas, considerando que o caminho da produção de conhecimento deve ser estabelecido a partir do diálogo com novos e outros saberes, gerando assim formas híbridas e integradas do conhecimento. Com base nesse entendimento, salientamos os riscos em insistir nos caminhos da produção do conhecimento a partir do racionalismo científico, fechado e linear. Conceber a ideia absoluta e unitária de produzir conhecimento científico pode levar a padronização da diversidade do real e reforçar as produções reducionistas e/ou simplistas da lógica do discurso final pronto e acabado. Há, portanto, um novo campo de conceber a produção conhecimento científico.

Vislumbrando tais entendimentos, neste artigo buscou-se ressaltar a compreensão do significado das formas de representações da bacia hidrográfica em âmbito acadêmicogeográfico e político-institucional. Ao considerar o referencial teórico-conceitual da bacia hidrográfica como recorte espacial ou unidade territorial para fins planejamento e gestão, bem como a unidade espacial de investigação acadêmica, foram ponderadas que há, nas representações, diversos significados e formas de leituras. Assim, tanto em estudos acadêmicos quanto em planos e ações na esfera pública e privada são observados múltiplos enfoques, entre outros, o ambiental, o social e o econômico, o político-institucional e o administrativo.

Ao adotarmos uma perspectiva de outras leituras e olhares, destacou-se que no recorte espacial da bacia hidrográfica há uma multiplicidade de implicações, internas e externas, onde muitos dos fenômenos estudados transcendem aos seus limites e fronteiras aparentemente naturais, mas constituídas pelo conhecimento produzido a partir da fragmentação e hierarquização. 
MARINHO, V.L.F. \& MORETTI, E.C. Os caminhos das águas: As políticas...

Portanto, no âmbito das políticas públicas ambientais voltadas aos recursos hídricos, especificando as bases de dados nacionais, socioeconômicos, censitários e de infraestrutura disponibilizados pelos municípios, não são obedecidos os limites de bacias hidrográficas. Dessa forma, faz-se necessário considerar que nas representações cartográficas das bacias hidrográficas se agregam, de forma total e/ou parcial, dados e informações fragmentadas. Assim, como identificar ou investigar no conjunto todas as representações dos atores sociais diretamente ou indiretamente interessados e envolvidos na tomada de decisões? Além disso, como identificar os significados da valoração, pertencimento e direitos sobre águas? Tais indagações ocorrem devido ao caráter multifuncional da água e aos seus múltiplos significados para a sociedade e ao modelo de desenvolvimento adotado.

Ao propor esta leitura, não se pode ocultar que na essência do enfoque técnico-científico há um conteúdo político e filosófico. E, ao ampliar o olhar, instiga-se a discussão sobre a produção e apropriação da natureza, exercício necessário à discussão inicialmente proposta. Sendo este o sentido observado através da discussão teórico-conceitual da bacia hidrográfica e sob o enfoque da tendência dos interesses voltados aos lugares aponta-se que, em muitos momentos, as questões transcendem ao local e assumem outros ou novos significados.

Enfim, na sociedade contemporânea, as preocupações sobre o ambiente, conservação e desenvolvimento assumem uma importância extra-acadêmica e perpassa as discussões estabelecidas em instâncias de poder administrativo e econômico, assim como representações político-institucionais e instrumentos jurídicos legais. Desse modo, nas últimas décadas do século XXI, observouse que as políticas públicas absorveram tais questões, porém, quanto às práticas, há muitas limitações e desafios a serem superados. 
MARINHO, V.L.F. \& MORETTI, E.C. Os caminhos das águas: As políticas...

\section{Referências bibliográficas}

ANA - Agência Nacional de Águas (Brasil). Conjuntura dos recursos hídricos no Brasil: informe 2012. Ed. Especial. Brasília: ANA, 2012. 215 p.: il. Disponível em: <http://arquivos.ana.gov.br/imprensa/arquivos/Conjuntura2012〉. Acesso em: janeiro 2013.

O Comitê de Bacia Hidrográfica: prática e procedimentos. Brasília: ANA, SAG, 2011. 81 p.: il. (Cadernos de capacitação em recursos hídricos; v. 2). Disponível em: <www.ana.gov.br> Acesso em: novembro de 2012.

BONETI, Lindomar Wessler. O silêncio das águas: políticas públicas, meio ambiente e exclusão social. Ijuí: Ed. UNIJUÍ, 1997. 244p.

BRASIL (República Federativa do Brasil). Constituição Federal de 1988. Brasília: Senado Federal, 1988. 292p.

LEI 9.433, de 8 de Janeiro de1997. Institui a Política Nacional Dos Recursos Hídricos. Brasília: 1997. Disponível em: <http://www.planalto.gov.br> Acesso em: julho 2011.

CAETANO, João Ricardo. Gestão de recursos hídricos em áreas de proteção de mananciais: o caso de Santo André, São Paulo. In: LITTLE, Paul (Org.) Políticas ambientais no Brasil: análises, instrumentos e experiências. São Paulo: IIEB, cap. 10. p. 261-270. 2003.

CASTRO, Frederico do Valle Ferreira de; ALVARENGA, Luciano José; MAGALHÃES JÚNIOR, Antônio Pereira. A Política Nacional de Recursos Hídricos e a gestão de conflitos em uma nova territorialidade. Geografias: Revista do Departamento de Geografia / Programa de Pós-graduação em Geografia, Departamento de Geografia do Instituto de Geociências, 
MARINHO, V.L.F. \& MORETTI, E.C. Os caminhos das águas: As políticas... UFMG. - v. 1, n. 1 (jul./dez.) 2005 - Belo Horizonte: UFMG, Departamento de Geografia, 2005.

CARVALHO, Silvia Méri. A contribuição dos estudos em bacias hidrográficas para a abordagem ambiental na Geografia. In: MENDONÇA, Francisco; LOWEN-SAHR, Cicilian Luiza; SILVIA, Márcia da (Org.). Espaço e Tempo: complexidades e desafios do pensar e do fazer geográfico. Curitiba: Associação de Defesa do Meio Ambiente e Desenvolvimento de Antonina (ADEMADAN), 2009. p. 2001-217.

DE SOUZA SANTOS, Boaventura. Um Discurso sobre as Ciências. $7^{\text {a }}$ edição. São Paulo: Edições Afrontamento, 1995. 57 p.

FERRAZ, Cláudio Benito Oliveira. O estudo geográfico dos elementos culturais. Considerações para além da geografia cultural. Departamento de Educação da FCT/UNESP de Presidente Prudente: 2008.

GONÇALVES, Calos Walter Porto. Da Geografia às Geografias: um mundo em busca de novas territorialidades. Argentina - Bueno Aires: Ed. Clasco. 2002. 217-256p. Disponível em: <biblioteca. clacso.edu.ar/ar/libros/cecena/porto.pdf >; Acesso em dezembro de 2012.

LEFF, Henrique. Epistemologia ambiental. São Paulo: Cortez. 2001, p.159-190.

MAGALHÃES JUNIOR, Antônio Pereira. Indicadores ambientais e recursos hídricos: realidade e perspectiva para o Brasil a partir da experiência francesa. Rio de Janeiro: Bertrand Brasil, 2007.

PAGNOCCHESCHI, Bruno. Política Nacional de Recursos Hídricos. In: LITTLE, Paul (Org.) Políticas ambientais no Brasil: 
MARINHO, V.L.F. \& MORETTI, E.C. Os caminhos das águas: As políticas... análises, instrumentos e experiências. São Paulo: IIEB, 2003.p. 239-315.

RODRIGUES, Arlete Moysés. Meio ambiente e desenvolvimento. Belo Horizonte: Escola de Governo da Fundação João Pinheiro, 2001.14p. (Curso de Gestão Urbana e de Cidades).

SHIVA, Vandana. Guerra por Águas: privatização, poluição e lucro. Tradução George Kormikiaris. São Paulo: Radical Livros, 2006, 168.p.

Recebido em junho de 2013 Aceito em julho de 2013 